\title{
Optimum Design of Transformer-Type Marchand Balun Using Scalable Integrated Passive Device Technology
}

\author{
Chien-Hsiang Huang, Tzyy-Sheng Horng, Senior Member, IEEE, Chen-Chao Wang, \\ Chi-Tsung Chiu, and Chih-Pin Hung
}

\begin{abstract}
A simple and effective technique for designing transformer-type Marchand baluns is presented in this paper. The coupled-line sections required in a Marchand balun design are realized using planar transformers with a scalable model. The proposed design technique enables the prediction and optimization of Marchand balun performance over a wide range of layout and process parameters. To demonstrate the optimization process, Marchand baluns are designed for implementation using silicon and glass integrated passive device (IPD) technologies. Finally, experimental verification shows very good agreement between the modeled and measured results, thereby validating the IPD design optimization.
\end{abstract}

Index Terms-Integrated passive device, Marchand balun, planar transformer, scalable model.

\section{INTRODUCTION}

A BALUN is an important component in balanced microwave front-end circuits such as balanced mixers [1], and push-pull amplifiers [2], and also in several other applications. Baluns are mainly used to convert an unbalanced input signal into two balanced output signals. Baluns can be further classified into active and passive baluns. The major advantage of active baluns is their small size, which makes them suitable for integration into integrated circuits. However, the performance of active baluns in terms of their linearity, noise figure, and balance property is usually unsatisfactory [3]. Passive baluns can be subclassified as lumped-element baluns and Marchand baluns. Lumped-element baluns provide balanced outputs only around the designed frequency, and the balance degrades severely at frequencies away from this frequency [4]. Marchand baluns [5] have received a great deal of attention because of their compact size, good balance

Manuscript received May 10, 2011; revised August 16, 2011; accepted September 12, 2011. Date of publication November 23, 2012; date of current version July 31, 2012. This work was supported in part by the National Science Council, Taiwan, under Grant 97-2221-E-110-034-MY3, Grant 97-2221-E-110-035-MY3, and Grant 99-2622-E-110-003-CC1, and the Department of Industrial Technology, Taiwan, under Grant 99-EC-17-A-01S1-104. Recommended for publication by Associate Editor R.-B. Wu upon evaluation of reviewers' comments.

C.-H. Huang and T.-S. Horng are with the Department of Electrical Engineering, National Sun Yat-Sen University, Kaohsiung 804, Taiwan (e-mail: d9131820@student.nsysu.edu.tw; jason@ee.nsysu.edu.tw).

C.-C. Wang, C.-T. Chiu, and C.-P. Hung are with the Research and Development Division, Advanced Semiconductor Engineering Inc., Kaohsiung 811, Taiwan (e-mail: Alexcc_Wang@aseglobal.com; ct_chiu@aseglobal.com; cp_hung@aseglobal.com).

Color versions of one or more of the figures in this paper are available online at http://ieeexplore.ieee.org.

Digital Object Identifier 10.1109/TCPMT.2011.2171514 performance, and wide operating frequency range. Marchand baluns can be made of coupled-line sections [6], Lange couplers [7], or planar transformers [8]. A Marchand balun that employs planar transformers has the advantages of a compact layout and increased mutual coupling, leading to a shorter required metal length for a given operating frequency. Hence, such a transformer-type Marchand balun has been widely used in double-balanced mixer radio frequency integrated circuit designs [9].

The Marchand balun model has been analyzed using a curve-fitting technique for the measurements [1]. However, it is difficult to correlate this type of empirical model with new or modified designs, because it is not directly linked to the physical parameters of the balun. Conversely, electromagnetic simulation can provide a physical-structure-based analysis [8], however, it requires long computation time and is not easy to tune the multiple parameters of the balun to achieve desired performance, especially when optimization has been enabled. Complicated analytical formulas for Marchand baluns have been reported [6], but the extension of this model to an equivalent circuit model is not straightforward. In general, distinct guidelines for the circuit design and optimization of Marchand baluns are not available.

In this paper, we propose a scalable transformer model in integrated passive device (IPD) technology to correlate with the coupled-line sections of a conventional Marchand balun. The coupled-line section can be modeled as an equivalent lumped transformer circuit based on our previous work [10]. This improves the efficiency of the design of planar transformers with equivalent coupled-line parameters such as the coupling factor, and even- and odd-mode characteristic impedances, and $Q$ factors. Additionally, the proposed model-based design approach provides effective optimization techniques that incorporate geometrical and material parameters. Accordingly, through the manufacture of IPD on silicon and glass substrates, this paper explores the achievement of transformer-type Marchand balun designs that are optimized for minimum insertion loss (IL) while providing good impedance matching and balance over a wide operating frequency range.

\section{IPD BALUN STRUCTURE}

The current trend toward further miniaturization of electronic system products increases the demands for their high 


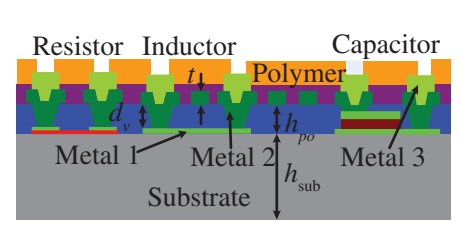

(a)

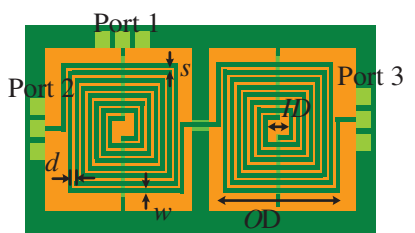

(b)
Fig. 1. (a) Cross-sectional view of thin-film integrated passive device structures. (b) Layout of Marchand balun using two planar transformers.

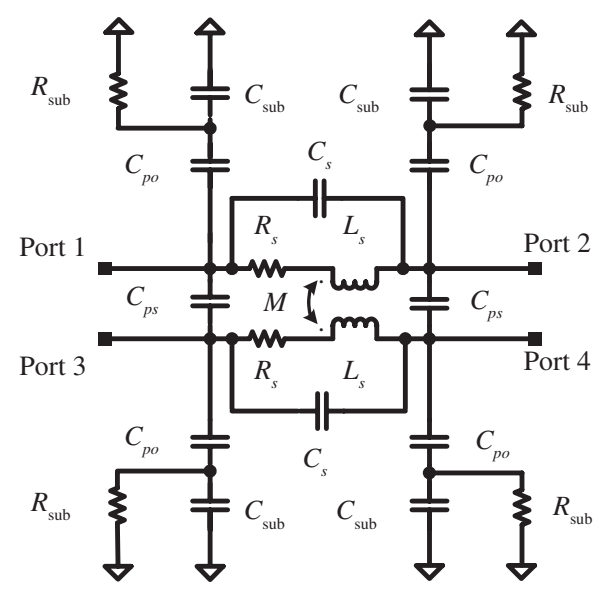

Fig. 2. Equivalent circuit of a symmetric transformer.

performance, increased reliability, and reduced cost. More functions continue to be added to electronic products, yet, their overall size continues to shrink. However, the use of a larger number of passive components in an electronic system will not only require a larger area but also increase the assembly cost. System-in-package (SiP) offers a promising solution for improving device performance and decreasing their size for high-volume applications of passive components. Among the various $\mathrm{SiP}$ approaches, the fabrication of wafer-level IPDs [11]-[13] is the most attractive way to overcome the abovementioned drawbacks. The main feature of such IPDs is that they are fabricated by the same process or an additional one during the fabrication of the devices on the wafer.

The IPDs described in this paper were constructed by applying thin-film process technology to specially prepared silicon-or-glass substrates. A cross section of the structure is shown in Fig. 1(a). It consists of three layers of metal with a polyimide interlevel dielectric. The bottom metal layer is used exclusively for the bottom electrodes of capacitors. This bottom layer is of aluminum, and the top two layers, used for inductor coils, are $10-\mu \mathrm{m}$ and $6-\mu \mathrm{m}$-thick layers of copper. The thin film build-up technology allows a high level of integration and meets the demands of basic passive elements, such as resistors, inductors, and capacitors. In this interconnection technology, it is possible to realize integrated passive components in the radio frequency (RF) front-end subsystem with high performance for wireless communication applications. Based on the above-mentioned fact that IPDs are generally fabricated by standard wafer fabrication technologies, it is possible to manufacture a small low-cost physical balun structure with excellent reproducibility.

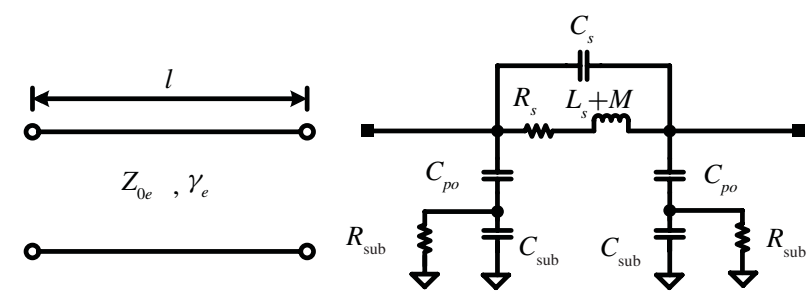

(a)

(b)

Fig. 3. Even-mode circuit. (a) Coupled-line section. (b) Symmetric transformer.

The basic circuit of a conventional Marchand balun consists of two coupled-line sections in a planar structure. The length of each coupled-line section at the desired center operating frequency should be equal to one-quarter wavelength. The coiling of the coupled-line section into a planar transformer is advantageous in that it increases the mutual inductance. Consequently, for a Marchand balun designed to operate in a particular frequency range, the transformer is more compact than the meander coupled-line sections because it requires a smaller overall length of wire [14]. As illustrated in Fig. 1(b), the transformer, which is composed of two coplanar rectangular spiral inductors with inner and outer windings, is symmetrical. The Marchand balun design is based on two transformers cascaded in series, which were fabricated by an IPD process on $700-\mu$ m-thick silicon and glass substrates with the layer structure depicted in Fig. 1(a).

\section{Marchand Balun Design with a Symmetric TRANSFORMER MODEL}

Fig. 2 shows the proposed equivalent circuit for the planar transformers of a transformer-type Marchand balun. Each element in the equivalent circuit of Fig. 2 has the following physical properties: $R_{S}$ denotes the series resistance values of the spiral metal coils; the self-inductance and mutual inductance of the transformer coils are denoted as $L_{s}$ and $M$, respectively; the capacitance $C_{p s}$ is used to model the mutual electrical coupling of the two interwound coils; $C_{s}$ denotes the inter-coil and underpass capacitance; $C_{p o}$ is the spiral coil-tosubstrate coupling capacitance; and $R_{\text {sub }}$ and $C_{\text {sub }}$ denote the lossy substrate resistance and capacitance, respectively.

In order to determine the conditions for model equivalence between the coupled-line section and the planar transformer, an even- and odd-mode analysis is employed, this analysis decomposes the circuits into two-port networks for simplifying the complexity of the problem [15], [16]. Figs. 3(a) and 4(a) show the even- and odd-mode circuits, respectively, of a coupled-line section. The characteristic impedances of the even- and odd-mode transmission lines can be denoted as $Z_{o e}$ and $Z_{0 o}$, respectively. The length of the coupled-line section is equal to $l$. The even- and odd-mode circuits corresponding to a symmetric transformer are shown in Figs. 3(b) and 4(b), respectively.

The $S$ parameters of a lossy transmission line with an electrical length of $\pi / 2$ that uses the even-mode characteristic impedance $Z_{0 e}$ or the odd-mode characteristic impedance $Z_{0 o}$, as shown in Figs. 3(a) and 4(a), respectively, can be obtained 
as follows:

$$
\begin{aligned}
& S_{21} 0 e=\frac{2}{j\left[2 \sinh \left(\frac{\pi}{4 Q_{0 e}}\right)+\left(\frac{Z_{0 e}}{Z_{0}}+\frac{Z_{0}}{Z_{0 e}}\right) \cosh \left(\frac{\pi}{4 Q_{0 e}}\right)\right]} \\
& S_{11} 0 e=\frac{\left(\frac{Z_{0 e}}{Z_{0}}-\frac{Z_{0}}{Z_{0 e}}\right) \cosh \left(\frac{\pi}{4 Q_{0 e}}\right)}{2 \sinh \left(\frac{\pi}{4 Q_{0 e}}\right)+\left(\frac{Z_{0 e}}{Z_{0}}+\frac{Z_{0}}{Z_{0 e}}\right) \cosh \left(\frac{\pi}{4 Q_{0 e}}\right)} \\
& S_{21} 0 o=\frac{2}{j\left[2 \sinh \left(\frac{\pi}{4 Q_{0 o}}\right)+\left(\frac{Z_{0 o}}{Z_{0}}+\frac{Z_{0}}{Z_{0 o}}\right) \cosh \left(\frac{\pi}{4 Q_{0 o}}\right)\right]} \\
& S_{11} 0 o=\frac{\left(\frac{Z_{0 o}}{Z_{0}}-\frac{Z_{0}}{Z_{0 o}}\right) \cosh \left(\frac{\pi}{4 Q_{0 o}}\right)}{2 \sinh \left(\frac{\pi}{4 Q_{0 o}}\right)+\left(\frac{Z_{0 o}}{Z_{0}}+\frac{Z_{0}}{Z_{0 o}}\right) \cosh \left(\frac{\pi}{4 Q_{0 o}}\right)}
\end{aligned}
$$

where $Z_{0}$ is the terminal impedance and $Q_{0 e}$ and $Q_{0 o}$ are the even- and odd-mode $Q$ factor, respectively. An analysis of a Marchand balun based on coupled-line section can generally obtain the following scattering matrix [17]:

$$
\begin{aligned}
& {[S]_{\text {Marchand balun }}=\left[\begin{array}{lll}
S_{11} & S_{12} & S_{13} \\
S_{21} & S_{22} & S_{23} \\
S_{31} & S_{32} & S_{33}
\end{array}\right]} \\
& \quad=\left[\begin{array}{ccc}
\frac{x_{1}+y_{1}-4 x_{1} y_{1}}{1-x_{1}-y_{1}} & \frac{x_{2}-2 x_{1} x_{2}}{1-x_{1}-y_{1}} & -\frac{x_{2}-2 x_{1} x_{2}}{1-x_{1}-y_{1}} \\
\frac{x_{2}-2 x_{1} x_{2}}{1-x_{1}-y_{1}} & \frac{\left(y_{2}-y_{1}\right)\left(1-x_{1}-y_{1}\right)+x_{2}^{2}}{1-x_{1}-y_{1}} & \frac{\left(y_{2}-y_{1}\right)\left(1-x_{1}-y_{1}\right)+x_{2}^{2}}{1-x_{1}-y_{1}} \\
-\frac{x_{2}-2 x_{1} x_{2}}{1-x_{1}-y_{1}} & \frac{\left(y_{2}-y_{1}\right)\left(1-x_{1}-y_{1}\right)+x_{2}^{2}}{1-x_{1}-y_{1}} & \frac{\left(y_{2}-y_{1}\right)\left(1-x_{1}-y_{1}\right)+x_{2}^{2}}{1-x_{1}-y_{1}}
\end{array}\right]
\end{aligned}
$$

where

$$
\begin{aligned}
& x_{1}=\frac{1}{2}\left[R+\frac{2 T C I-T^{2}(R+1)-C^{2}(R-1)}{(R+1)(R-1)-I^{2}}\right] \\
& y_{1}=\frac{1}{2}\left[R+\frac{2 T C I-T^{2}(R+1)-C^{2}(R+1)}{(R+1)^{2}-I^{2}}\right] \\
& x_{2}=\frac{1}{2}\left[I+\frac{I\left(T^{2}+C^{2}\right)-2(R+1) T C}{(R+1)^{2}-I^{2}}\right] \\
& y_{2}=\frac{1}{2}\left[R+\frac{2 T C I-T^{2}(R-1)-C^{2}(R+1)}{(R+1)(R-1)-I^{2}}\right]
\end{aligned}
$$

with $R, T, C$, and $I$ denoting the reflection, transmission, coupling, and isolation coefficient, respectively, of the coupledline section. With the help of even- and odd-mode analysis [18], the four coefficients $R, T, C$, and $I$ can be determined in terms of the even- and odd-mode scattering parameters that are shown in (1)-(4). With (10), the IL of a balun can be further estimated as [8]

$$
I L \approx-10 \cdot \log \left(\left|S_{21}\right|^{2}+\left|S_{31}\right|^{2}\right)(\mathrm{dB}) .
$$

The common-mode rejection ratio (CMRR) is a figure of merit for characterizing a three-port Marchand balun and is widely used to evaluate the performance of balanced circuits. CMRR is defined as the ratio of the magnitude of the differential mode transmission coefficient to that of the common mode transmission coefficient [19]. The CMRR of a three-port balun can be expressed in terms of the three port single-ended $S$ parameters as

$$
\mathrm{CMRR}=20 \cdot \log \left(\left|\frac{S_{21}-S_{31}}{S_{21}+S_{31}}\right|\right)(\mathrm{dB}) .
$$

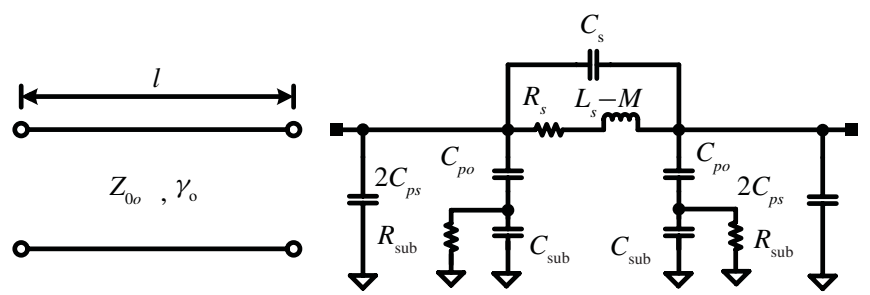

(a)

(b)

Fig. 4. Odd-mode circuit. (a) Coupled-line section. (b) Symmetric transformer.

Equations (5)-(9) indicate that the balun design can be reduced to an optimum coupled-line design. As mentioned above, a coupled-line section is equivalent to the four-port symmetric transformer model. Thus, the values of $Z_{0 e}$ and $Z_{0 o}$ can be derived by equating their even-mode circuit and odd-mode circuit, respectively, and are expressed as follows:

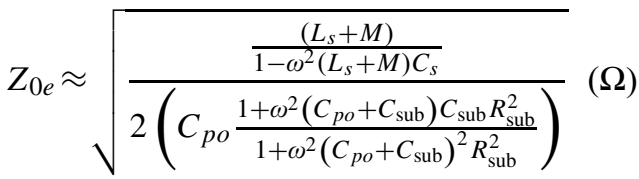

$$
\begin{aligned}
& Z_{0 o} \approx \sqrt{\frac{\frac{\left(L_{s}-M\right)}{1-\omega^{2}\left(L_{s}-M\right) C_{s}}}{2\left(C_{p o} \frac{1+\omega^{2}\left(C_{p o}+C_{\mathrm{sub}}\right) C_{\mathrm{sub}} R_{\mathrm{sub}}^{2}}{1+\omega^{2}\left(C_{p o}+C_{\mathrm{sub}}\right)^{2} R_{\mathrm{sub}}^{2}}+2 C_{p s}\right)}}(\Omega) .
\end{aligned}
$$

The most popular definition of the $Q$ factor of a transmission line is that it is the ratio of the phase constant $\beta$ to twice the attenuation constant $\alpha$ [18]. What follows indicates the procedure for extracting the effective complex propagation constant $(\gamma=\alpha+j \beta)$ from the modeled two-port $S$ parameters. As shown in Figs. 3(a) and 4(a), the even-mode complex propagation constant $\gamma_{e}$ and the odd-mode complex propagation constant $\gamma_{o}$ were extracted from the two-port $S$ parameters as [20]

$$
\begin{aligned}
e^{\gamma_{i} l} & =e^{\left(\alpha_{i}+j \beta_{i}\right) l} \\
& =\frac{1-S_{11, i}^{2}+S_{21, i}^{2}+\sqrt{\left(S_{11, i}^{2}-S_{21, i}^{2}+1\right)^{2}-\left(2 S_{11, i}^{2}\right)^{2}}}{2 S_{21, i}}
\end{aligned}
$$

where $i=e$ or $o$, and $\gamma_{i}, \alpha_{i}$, and $\beta_{i}$ are the complex propagation constant, attenuation constant, and phase constant of mode $i$, respectively.

Starting from the proposed transformer model for Marchand baluns, scalable physical lumped models for transformers can be developed, and the model elements can be determined from an analytical expression that uses the geometric and process technology data. With a physical parameterized layout scheme, the designer can quickly optimize the planar transformer geometry that best suits the needs of Marchand balun designs. Further details will be discussed in the following sections.

\section{Transformer Model with Scalability}

The exact self-inductances of the primary and secondary ports of the symmetrical transformer can be calculated using 
TABLE I

Summary of Even- and Odd-Mode Parameters and Balun Performance by Varying the WidTh AND SPACING OF A TRANSFORMER IN SILICON IPD TECHNOLOGY

\begin{tabular}{|c|c|c|c|c|c|c|c|c|}
\hline $\begin{array}{c}(w, s) \\
(\mu \mathrm{m}, \mu \mathrm{m})\end{array}$ & $\begin{array}{l}Z_{0 e} \\
(\Omega)\end{array}$ & $\begin{array}{l}Z_{0 o} \\
(\Omega)\end{array}$ & $Q_{0 e}$ & $Q_{0 o}$ & $\begin{array}{c}I L \\
(\mathrm{~dB})\end{array}$ & $\begin{array}{c}R L \\
(\mathrm{~dB})\end{array}$ & $\begin{array}{c}\text { Bandwidth } \\
(\%)\end{array}$ & $\begin{array}{c}\text { CMRR } \\
(\mathrm{dB})\end{array}$ \\
\hline$(10,10)$ & 445.4 & 41.9 & 2.6 & 4.4 & 2.8 & 13.6 & 159 & 28.9 \\
\hline$(10,20)$ & 441.9 & 64.6 & 2.7 & 5.9 & 3.4 & 5.1 & 63 & 25.7 \\
\hline$(10,30)$ & 440.2 & 82.2 & 2.8 & 6.5 & 5 & 3.2 & 44 & 22.2 \\
\hline$(20,10)$ & 347.6 & 40.7 & 3.2 & 7.3 & 2 & 13.9 & 133 & 29.4 \\
\hline$(20,20)$ & 343.6 & 59.5 & 3.4 & 8.2 & 3.4 & 5.9 & 60 & 22.4 \\
\hline$(20,30)$ & 340.2 & 73.8 & 3.4 & 8.3 & 4.9 & 4 & 38 & 18.7 \\
\hline$(30,10)$ & 282.9 & 38.8 & 4.9 & 9.6 & 1.5 & 14.4 & 112 & 27.7 \\
\hline$(30,20)$ & 281.6 & 56.2 & 5.3 & 11 & 3 & 5.9 & 52 & 22.3 \\
\hline$(30,30)$ & 280 & 64.4 & 5.5 & 11.4 & 3.9 & 4.3 & 37 & 18.5 \\
\hline$(40,10)$ & 241.4 & 41.2 & 5.6 & 10.8 & 1.7 & 11.4 & 110 & 20.5 \\
\hline$(40,20)$ & 239.9 & 55.6 & 6 & 11.1 & 3.4 & 5.6 & 42 & 18.6 \\
\hline$(40,30)$ & 238.1 & 65.9 & 6.3 & 12 & 4.4 & 3.8 & 26 & 15.6 \\
\hline
\end{tabular}

the empirical formula provided in [21] for general planar inductors

$$
L_{s}=2 l\left(\ln \frac{2 l}{w+t}+0.5+\frac{w+t}{3 l}\right)(n H)
$$

where $l, w$, and $t$ denote the length, width, and thickness, respectively, of the coiled conductor strip in centimeters. When designing a balun, it is first necessary to determine the length of the interwinding metal strip. By analogy with the coupled-line theory, the band center occurs at the quarterwavelength resonant frequency of the individual segments. The metal lines of the nested spiral inductors are equivalent to quarter-wavelength electrical lengths at the designed operating frequency. The mutual inductance $M$ between two parallel conductors of equal length $l$ and the geometric mean distance (GMD) are given by [22]

$$
M=2 l Q_{m}(n H)
$$

where

$$
\begin{aligned}
Q_{m}= & \ln \left[\frac{l}{G M D}+\sqrt{1+\left(\frac{l}{G M D}\right)^{2}}\right] \\
& -\sqrt{1+\left(\frac{G M D}{l}\right)^{2}}+\frac{G M D}{l} \\
\ln G M D \approx & \ln d-\frac{w^{2}}{12 d^{2}}-\frac{w^{4}}{60 d^{4}}-\frac{w^{6}}{168 d^{6}} \\
& -\frac{w^{8}}{360 d^{8}}-\frac{w^{10}}{660 d^{10}} .
\end{aligned}
$$

Note that GMD is a function of the coil conductor strip width $(w)$ and the distance $(d)$ between the primary and secondary coils in a transformer. In Fig. 1(b), the distance $d$ is equal to the sum of the conductor strip width $w$ and spacing $s$.

The self-capacitance and mutual capacitance are approximately calculated based on a parallel-plate structure using the following equations [23]:

$$
\begin{aligned}
C_{s} & =N_{t} w^{2} \frac{\varepsilon_{p o}}{d_{v}}(F) \\
C_{p s} & =\frac{1}{2} \varepsilon_{p o} \frac{t l}{s}(F) \\
C_{p o} & =\frac{1}{2} l w \frac{\varepsilon_{p o}}{t_{p o}}(F) \\
C_{\text {sub }} & =\frac{1}{2} l w C_{\text {suba }}(F)
\end{aligned}
$$

where $N_{t}$ is the number of crossovers in winding a coil, $\varepsilon_{p o}$ is the polymer permittivity, $d_{v}$ is the height of a via between metals 1 and 2, $t_{p o}$ is the polymer dielectric thickness, and $C_{\text {suba }}$ is the substrate capacitance per unit area.

Some resistances are included in the equivalent lumped models to account for the frequency-dependent losses, as shown in Fig. 2. The series resistance $R_{S}$ is used to model the conductor loss dominant at lower frequencies, whereas $R_{\text {sub }}$ is used to model the substrate loss dominant at higher frequencies. The estimation of the conductor loss resistance $R_{S}$, which is based on [24], uses the following expression considering the skin depth:

$$
R_{S}=\frac{l}{w \sigma_{c} \delta\left(1-e^{-t / \delta}\right)}(\Omega)
$$

where $\sigma_{c}$ and $\delta$ denote the metal conductivity and skin depth, respectively. $R_{\text {sub }}$ can be determined using the formula addressed in [25]

$$
\begin{aligned}
R_{\text {sub }}= & \frac{1}{\pi \sigma_{\text {sub }} l_{m p}} \\
& \times \ln \left[2 \operatorname{coth}\left(\frac{\pi}{8} \cdot \frac{w+6 h_{p o}+t}{h_{\text {sub }}}\right)\right](\Omega)
\end{aligned}
$$

where $l_{m p}$ is the mean perimeter of the primary turns, $h_{p o}$ is the distance between the strip and the substrate, and $\sigma_{\text {sub }}$ and $h_{\text {sub }}$ are the conductivity and thickness of the substrate, respectively. 
TABLE II

Summary of Even- And Odd-Mode Parameters and Balun Performance by Varying the WidTh AND SPACING OF A TRANSFORMER IN GLASS IPD TECHNOLOGY

\begin{tabular}{|c|c|c|c|c|c|c|c|c|}
\hline $\begin{array}{c}(w, s) \\
(\mu \mathrm{m}, \mu \mathrm{m})\end{array}$ & $\begin{array}{l}Z_{0 e} \\
(\Omega)\end{array}$ & $\begin{array}{l}Z_{0 o} \\
(\Omega)\end{array}$ & $Q_{0 e}$ & $Q_{0 o}$ & $\begin{array}{c}I L \\
(\mathrm{~dB})\end{array}$ & $\begin{array}{c}R L \\
(\mathrm{~dB})\end{array}$ & $\begin{array}{c}\text { Bandwidth } \\
(\%)\end{array}$ & $\begin{array}{c}\text { CMRR } \\
(\mathrm{dB})\end{array}$ \\
\hline$(10,10)$ & 525.8 & 40 & 48.9 & 7.7 & 1.5 & 15.5 & 122 & 29.4 \\
\hline$(10,20)$ & 517.5 & 63.1 & 48.8 & 12.2 & 2.7 & 5.1 & 47 & 25.2 \\
\hline$(10,30)$ & 511.2 & 81.6 & 48.8 & 15.5 & 4.3 & 2.8 & 28 & 22.1 \\
\hline$(20,10)$ & 369.6 & 38.3 & 48.8 & 11.8 & 1 & 15.8 & 114 & 32.5 \\
\hline$(20,20)$ & 364.8 & 57.3 & 49.1 & 17.3 & 2.3 & 5.4 & 41 & 23.9 \\
\hline$(20,30)$ & 359.8 & 71.5 & 49.2 & 21 & 3.6 & 3.2 & 21 & 20.8 \\
\hline$(30,10)$ & 302.4 & 37.4 & 35.6 & 11 & 1.2 & 15.9 & 108 & 25.7 \\
\hline$(30,20)$ & 298.8 & 54.5 & 36.3 & 18.5 & 2.1 & 5.8 & 38 & 20.4 \\
\hline$(30,30)$ & 296.2 & 65.7 & 36.8 & 21.8 & 3.3 & 3.6 & 12 & 17.7 \\
\hline$(40,10)$ & 268.9 & 35.9 & 22 & 10 & 1.3 & 13.1 & 106 & 20.8 \\
\hline$(40,20)$ & 264.1 & 52.4 & 23 & 10.2 & 2.5 & 6.4 & 48 & 18.1 \\
\hline$(40,30)$ & 262 & 62.3 & 26 & 12 & 3.5 & 4.2 & 25 & 16.6 \\
\hline
\end{tabular}

\section{Design Optimization And Results}

On the basis of (5) and (10), the designed optimizations of high-performance Marchand baluns with different combinations of the geometric conductor linewidth $w$ and line spacing $s$ of a transformer are listed in Tables I and II for an IPD process on a silicon substrate and a glass substrate, respectively. These tables summarize the extracted results of a transformer-type Marchand balun design with the central frequency of $2.45 \mathrm{GHz}$. The geometric parameters $w$ and $s$ can be properly selected on the basis of the limitations of the fabrication process. The conductor width $w$ ranges from 10 to $40 \mu \mathrm{m}$ and the spacing $s$ of the coupled line ranges from 10 to $30 \mu \mathrm{m}$. It is seen that the even-mode characteristic impedance value can be decreased, the oddmode characteristic impedance value can be increased, and the bandwidth can be reduced by increasing the metal mutual spacing, because of weakened coupling. In addition, the oddmode characteristic impedance value is more sensitive to changes in $s$ between the lines than the even-mode value. The minimum values of $w$ and $s$, which are both equal to $10 \mu \mathrm{m}$, are defined by the foundry rules, highlighting the process limitations on performance syntheses of transformertype Marchand baluns.

From these tables, we can also see that the return loss (RL) is relatively independent of the substrate materials for a given structure. The RL is mainly determined by the effective characteristic impedance of the coupled-line structure. The $\mathrm{RL}$ at the center frequency was found to be between 11 and $16 \mathrm{~dB}$ for the minimum spacing of $10 \mu \mathrm{m}$, as can be observed from the tables. Interestingly, it is noted that the transformertype Marchand balun designs on silicon and glass substrates can yield a wider bandwidth, significantly larger than $100 \%$, and a high CMRR ( $>20 \mathrm{~dB}$ ) with good matching when $s$ is chosen as $10 \mu \mathrm{m}$ and $w$ is in the range of 10 to $40 \mu \mathrm{m}$. The bandwidth of the balun is primarily determined by $s$ and is relatively sensitive to the mutual coupling of the coupled line. Increasing line spacing is equivalent to decreasing the mutual

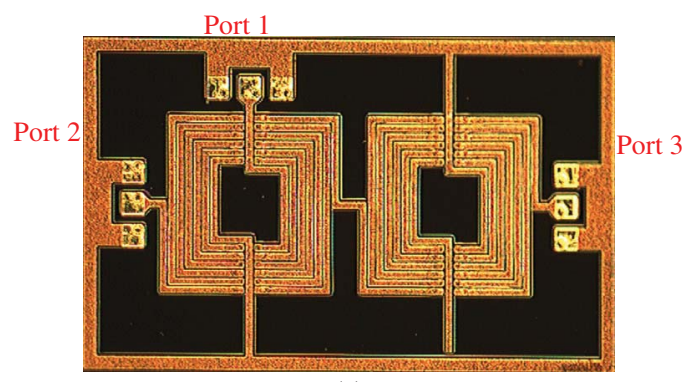

(a)

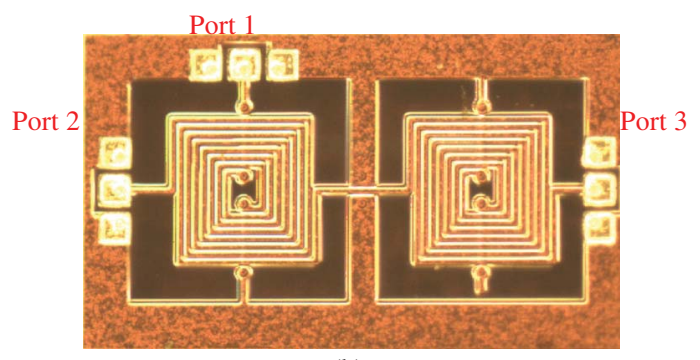

(b)

Fig. 5. Chip photographs of Marchand baluns fabricated by (a) silicon IPD and (b) glass IPD technologies.

coupling, which determines the bandwidth of the balun. With combinations of $s=10 \mu \mathrm{m}$ and $w=30 \mu \mathrm{m}$ for the silicon substrate and $s=10 \mu \mathrm{m}$ and $w=20 \mu \mathrm{m}$ for the glass substrate, the desired designs can yield well-matched high performances, including the lowest IL with good impedance matching and high CMRR over a wide bandwidth. The lowest IL of the baluns on the silicon and glass substrates is 1.5 and $1 \mathrm{~dB}$, respectively.

To validate the optimized designs and their performance, Marchand baluns with the above-specified linewidth and spacing were implemented using IPD technology on silicon and glass substrates. Measurements were carried out on an Agilent RF four-port electrical network analyzer (ENA) (ENA, E5071B), and a cascade on-wafer RF probe station using a probe tip pitch of $150 \mu \mathrm{m}$, with short-open-load- 


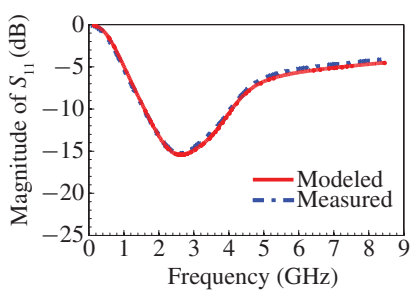

(a)

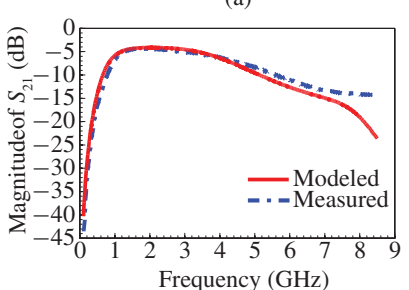

(c)

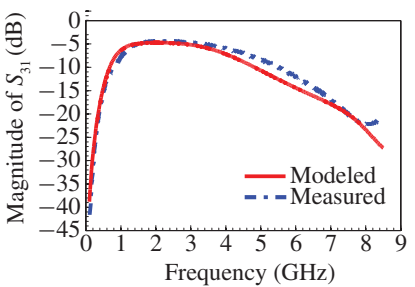

(e)

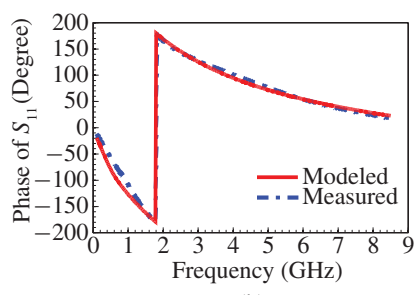

(b)

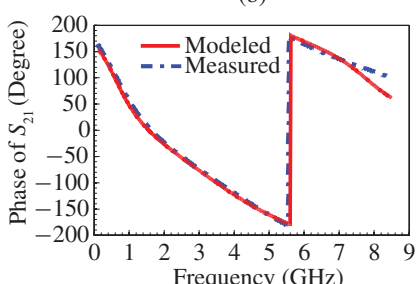

(d)

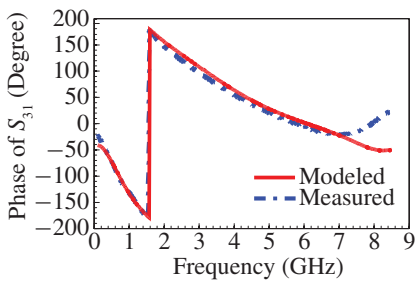

(f)

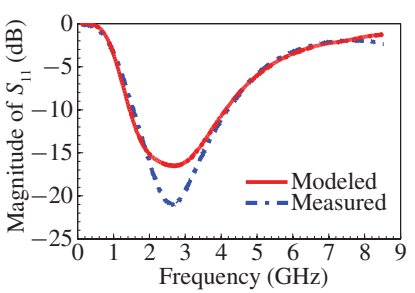

(a)

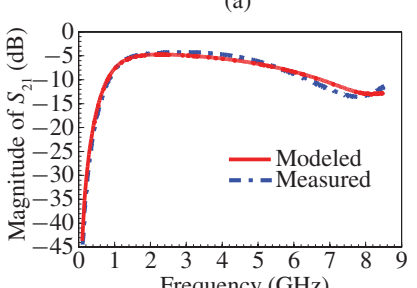

(c)

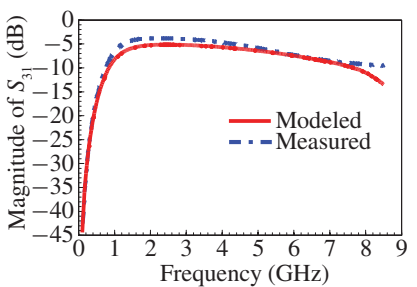

(e)

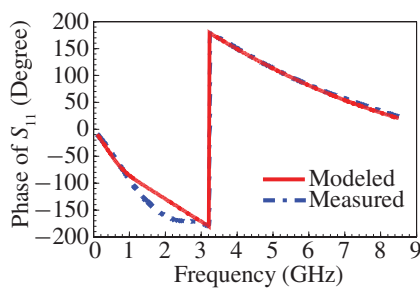

(b)

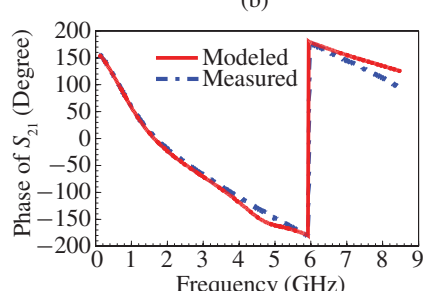

(d)

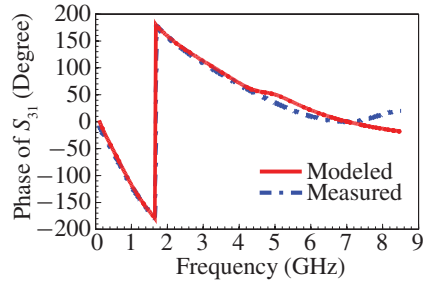

Fig. 6. Comparisons of modeled and measured $S$-parameters of the Marchand balun in silicon IPD technology (a) magnitude of $S_{11}$, (b) phase of $S_{11}$, (c) magnitude of $S_{21}$, (d) phase of $S_{21}$, (e) magnitude of $S_{31}$, and (f) phase of $S_{31}$.

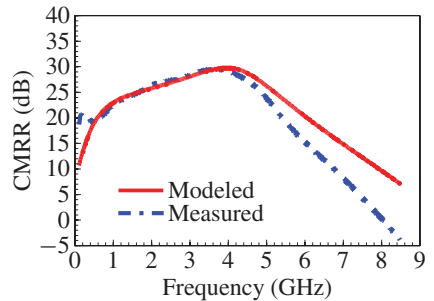

(a)

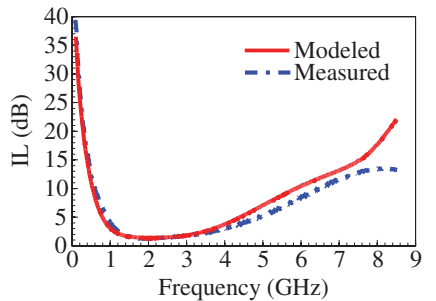

(b)

Fig. 7. Modeled and measured results of the Marchand balun in silicon IPD technology. (a) CMRR and (b) IL.

through/reciprocal (SOLT/SOLR) probe-tip calibrations performed beforehand. Fig. 5(a) and (b) shows photographs of Marchand baluns fabricated by IPD technology on silicon and glass substrates, where the chip dimensions of the baluns were $1.7 \times 0.8$ and $1.8 \times 0.7 \mathrm{~mm}^{2}$, respectively.

\section{A. Marchand Balun in Silicon IPD Technology}

The $S$ parameters of the Marchand balun that was fabricated in the silicon IPD process were measured by an on-wafer measurement technique. Furthermore, the balun was modeled using the above-mentioned analysis and the measured results were compared. Fig. 6 shows comparisons of the modeled and measured results for the magnitude and phase responses of the proposed silicon-substrate-based IPD Marchand balun. Obviously, good agreement was achieved between the measurement and modeling results. As shown in Fig. 6(a), the measured $\mathrm{RL}$ was found to be better than $10 \mathrm{~dB}$ in the frequency band 1.5-4.1 GHz, the measured transmission loss was approxi-

Fig. 8. Comparisons of modeled and measured $S$-parameters of the Marchand balun in glass IPD technology (a) magnitude of $S_{11}$, (b) phase of $S_{11}$, (c) magnitude of $S_{21}$, (d) phase of $S_{21}$, (e) magnitude of $S_{31}$, and (f) phase of $S_{31}$.

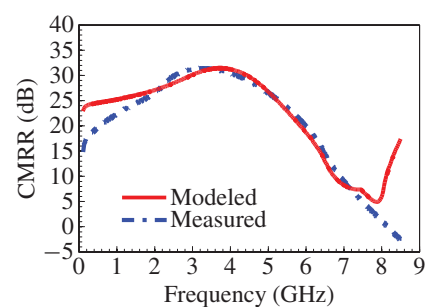

(a)

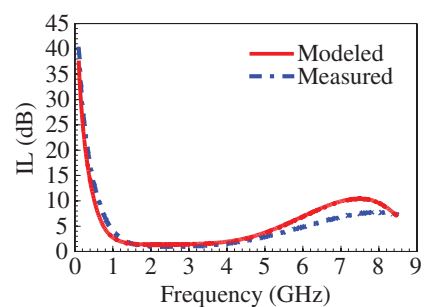

(b)
Fig. 9. Modeled and measured results for the Marchand balun in glass IPD technology. (a) CMRR. (b) IL.

mately $4.5 \mathrm{~dB}$ around the designed $2.45 \mathrm{GHz}$. The IL deviated from the ideal value by only $1.5 \mathrm{~dB}$.

Fig. 6(c)-(f) shows the results of the balun's transmission magnitude and phase responses $S_{21}$ and $S_{31}$. The magnitude imbalance and phase imbalance are calculated as $20 \log _{10}\left(\left|S_{21} / S_{31}\right|\right)$ and $180^{\circ}-\left|\angle\left(S_{21}\right)-\angle\left(S_{31}\right)\right|$, respectively. From the measured results, the magnitude and phase imbalance are $0.3 \mathrm{~dB}$ and $2.5^{\circ}$, respectively, at the designed center frequency of $2.45 \mathrm{GHz}$. Fig. 7(a) shows the frequency dependence of the measured CMRR of $27 \mathrm{~dB}$ at $2.45 \mathrm{GHz}$. The IL, which is discussed later, is shown in Fig. 7(b). The minimum IL achieved at $2.45 \mathrm{GHz}$ was about $1.5 \mathrm{~dB}$, which is almost the same as that predicted by the proposed transformer model.

\section{B. Marchand Balun in Glass IPD Technology}

The modeled and measured $S$ parameters of a glasssubstrate-based IPD Marchand balun are shown in Fig. 8. It can be seen from this figure that the modeled results 
TABLE III

COMPARISONS OF THE PERFORMANCES OF TRANSFORMER-TYPE MARCHAND BALUNS

\begin{tabular}{|c|c|c|c|c|c|c|c|c|}
\hline Ref. & $\begin{array}{c}\text { Center } \\
\text { frequency } \\
(\mathrm{GHz})\end{array}$ & $\begin{array}{c}10-\mathrm{dB} R L \\
\text { bandwidth } \\
(\%)\end{array}$ & $\begin{array}{c}\text { In-band } \\
\text { IL } \\
\text { (dB) }\end{array}$ & $\begin{array}{c}\text { In-band } \\
\text { magnitude } \\
\text { imbalance }(\mathrm{dB})\end{array}$ & $\begin{array}{c}\text { In-band } \\
\text { phase imbalance } \\
\text { (degree) }\end{array}$ & $\begin{array}{l}\text { In-band } \\
\text { CMRR } \\
(\mathrm{dB})\end{array}$ & $\begin{array}{c}\text { Size } \\
\left(\mathrm{mm}^{2}\right)\end{array}$ & $\begin{array}{l}\text { Substrate } \\
\text { technology }\end{array}$ \\
\hline [26] & 3 & 116 & $<1.3$ & $<0.5$ & $<15$ & $>17$ & $1.2 \times 2.3$ & Silicon IPD \\
\hline [27] & 3 & 136 & $<2$ & $<0.5$ & $<14$ & $>18$ & $1.1 \times 2.1$ & Silicon IPD \\
\hline [28] & 2.4 & 83 & $<2$ & $<1.5$ & $<6$ & $>19$ & $7 \times 4$ & Organic PD \\
\hline This paper & 2.45 & 106 & $<1.5$ & $<0.4$ & $<7$ & $>24$ & $1.7 \times 0.8$ & Silicon IPD \\
\hline This paper & 2.45 & 110 & $<1$ & $<1$ & $<2$ & $>24$ & $1.8 \times 0.7$ & Glass IPD \\
\hline
\end{tabular}

are in good agreement with the measured ones. Fig. 8(a) also shows that the measured RL is well matched and equal to $20 \mathrm{~dB}$ at about $2.45 \mathrm{GHz}$ and found to be better than $10 \mathrm{~dB}$ in the frequency band 1.5-4.2 GHz. Fig. 8(c)-(f) shows the results of the balun's transmission magnitude and phase responses $S_{21}$ and $S_{31}$. As was calculated from the measured results, the magnitude and phase imbalance at the designed center frequency of $2.45 \mathrm{GHz}$ are $0.45 \mathrm{~dB}$ and $2.8^{\circ}$, respectively. Fig. 9(a) and (b) shows the plots of the CMRR performance and IL, respectively, of the glass-substrate-based IPD Marchand balun. At $2.45 \mathrm{GHz}$, the measured CMRR is $29 \mathrm{~dB}$. The measured minimum IL is around $1 \mathrm{~dB}$ better than in the case of the silicon-substrate-based IPD Marchand balun design at the designed $2.45 \mathrm{GHz}$.

Table III presents a comparison of the 10-dB RL bandwidth, occupied size, in-band magnitude, phase imbalance, and CMRR of the transformer-type Marchand baluns to those of the previously reported ones [26]-[28] implemented using various fabrication technologies. Notably, the ratio of the frequency range with more than $10-\mathrm{dB}$ return loss to the nominal center frequency is referred to as the in-band bandwidth in percent. In addition to the in-band bandwidth, the in-band IL, magnitude imbalance, phase imbalance, and CMRR of the proposed balun are also compared with those reported in the previous works, as seen in Table III. The in-band CMRR of the proposed baluns is higher than that in the previous works because of the excellent performance of the former in terms of magnitude and phase imbalance. Although the reference designs [26], [27] have in-band bandwidths of $116 \%$ and $136 \%$, respectively, the measured minimum IL and in-band CMRR are somewhat higher than $1 \mathrm{~dB}$ and lower than $20 \mathrm{~dB}$. As shown in Table III, the proposed balun implemented on the IPD glass substrate has the lowest IL with a comparable inband bandwidth exceeding $100 \%$ and an excellent CMRR over the in-band frequency range. Overall, the baluns developed and reported in this paper yield minimum IL with excellent CMRR performance within a small chip area. Notably, the chip area is an essential parameter to consider during the integration of an on-chip passive device into an RF circuit, especially when implemented in IPD technology. These performance characteristics are good enough to be directly applied to wireless local area network and Bluetooth products.

\section{CONCLUSiON}

In this paper, transformer-type Marchand baluns consisting of multiple layers of metal and polyimide were designed, fabricated, and measured. Baluns with a transformertype configuration were fabricated by IPD technology on silicon and glass substrates. The developed baluns with good magnitude balance and phase balance displayed higher in-band CMRR performances than previously developed baluns, including excellent ILs for $2.45-\mathrm{GHz}$ wireless applications. In addition, a novel design procedure for Marchand baluns using a scalable transformer model was proposed. Because the model parameters were based on lumped values extracted from the physical structures of the devices, the models were useful for predicting the major characteristics from the design parameters of the baluns. The measurement results confirmed that the proposed model captured all the important features of the behaviors of transformer-type Marchand baluns. The measured results were validated by comparisons with modeling results obtained using the proposed model predictions. We believe that this balun design can be successfully employed in commercial applications.

\section{REFERENCES}

[1] T. Chen, K. W. Chang, S. B. Bui, H. Wang, G. Samuel, L. C. T. Lui, T. S. Lin, and W. S. Titus, "Broadband monolithic passive baluns and monolithic double-balanced mixer," IEEE Trans. Microw. Theory Tech., vol. 39, no. 12, pp. 1980-1986, Dec. 1991.

[2] P. C. Hsu, C. Nguyen, and M. Kintis, "Uniplanar broad-band push-pull FET amplifiers," IEEE Trans. Microw. Theory Tech., vol. 45, no. 12, pp. 2150-2152, Dec. 1997.

[3] B. Welch, K. T. Kornegay, H. M. Park, and J. Laskar, "A 20-GHz low-noise amplifier with active balun in a $0.25-\mu \mathrm{m}$ SiGe BICMOS technology," IEEE J. Solid-State Circuits, vol. 40, no. 10, pp. 2092 2097, Oct. 2005.

[4] J. C. Park, J. Y. Park, and H. S. Lee, "Fully embedded 2.4 GHz LCbalun into organic package substrate with series resonant tank circuit," in Proc. IEEE MTT-S Int. Microw. Symp. Dig., Honolulu, HI, Jun. 2007, pp. 1901-1904.

[5] N. Marchand, "Transmission line conversion transformers," Electronics, vol. 17, no. 12, pp. 142-146, Dec. 1944.

[6] R. Schwindt and C. Nguyen, "Computer-aided analysis and design of a planar multilayer Marchand balun," IEEE Trans. Microw. Theory Tech., vol. 42, no. 7, pp. 1429-1434, Jul. 1994.

[7] M. C. Tsai, "A new compact wideband balun," in Proc. IEEE MTT-S Int. Microw. Symp. Dig., vol. 1. Atlanta, GA, Jun. 1993, pp. 141-143.

[8] Y. J. Yoon, Y. Lu, R. C. Frye, M. Y. Lau, P. R. Smith, L. Ahlquist, and D. P. Kossives, "Design and characterization of multilayer spiral transmission-line baluns," IEEE Trans. Microw. Theory Tech., vol. 47, no. 9, pp. 1841-1847, Sep. 1999.

[9] S.-C. Tseng, C. Meng, C.-H. Chang, C.-K. Wu, and G.-W. Huang, "Monolithic broadband Gilbert micromixer with an integrated Marchand balun using standard silicon IC process," IEEE Trans. Microw. Theory Tech., vol. 54, no. 12, pp. 4362-4371, Dec. 2006.

[10] C.-H. Huang, C.-H. Chen, and T. S. Horng, "Design of integrated planar Marchand balun using physical transformer model," in Proc. Asia-Pacific Microw. Conf., Singapore, Dec. 2009, pp. 1004-1007. 
[11] H. M. Clearfield, J. L. Young, S. D. Wijeyesekera, and E. A. Logan, "Wafer-level chip scale packaging: Benefits for integrated passive devices," IEEE Trans. Adv. Packag., vol. 23, no. 2, pp. 247-251, May 2000.

[12] G. Carchon, K. Vaesen, S. Brebels, W. D. Raedt, E. Beyne, and B. Nauwelaers, "Multilayer thin-film MCM-D for the integration of highperformance RF and microwave circuits," IEEE Trans. Comp. Packag. Technol., vol. 24, no. 3, pp. 510-519, Sep. 2001.

[13] K. Zoschke, M. J. Wolf, M. Töpper, O. Ehrmann, T. Fritzsch, K. Kaletta, F. Schmückle, and H. Reichl, "Fabrication of application specific integrated passive devices using wafer level packaging technologies," IEEE Trans. Adv. Packag., vol. 30, no. 3, pp. 359-368, Aug. 2007.

[14] M. Shimozawa, K. Itoh, Y. Sasaki, H. Kawano, Y. Isota, and O. Ishida, "A parallel connected Marchand balun using spiral shaped equal length coupled lines," in Proc. IEEE MTT-S Int. Microw. Symp. Dig., vol. 4. Anaheim, CA, Jun. 1999, pp. 1737-1740.

[15] J. Reed and G. J. Wheeler, "A method of analysis of symmetrical fourport networks," IRE Trans. Microw. Theory Tech., vol. 4, no. 4, pp. 246-252, Oct. 1956.

[16] R. Mongia, I. Bahl, and P. Bhartia, RF and Microwave Coupled-Line Circuits. Norwood, MA: Artech House, 1999.

[17] K. S. Ang and I. D. Robertson, "Analysis and design of impedancetransforming planar Marchand baluns," IEEE Trans. Microw. Theory Tech., vol. 49, no. 2, pp. 402-406, Feb. 2001.

[18] D. M. Pozar, Microwave Engineering, 3rd ed. New York: Wiley, 2005.

[19] W. R. Eisenstadt, B. Stengel, and B. M. Thompson, Microwave Differential Circuit Design Using Mixed-Mode S-Parameters. Norwood, MA: Artech House, 2006.

[20] W. R. Eisenstadt and Y. Eo, "S-parameter-based IC interconnect transmission line characterization," IEEE Trans. Comp., Hyb., Manuf. Technol., vol. 15, no. 4, pp. 483-490, Aug. 1992.

[21] H. M. Greenhouse, "Design of planar rectangular microelectronic inductors," IEEE Trans. Parts, Hyb., Packag., vol. 10, no. 2, pp. 101-109, Jun. 1974.

[22] F. W. Grover, Inductance Calculations. New York: Van Nostrand, 1962.

[23] C. P. Yue and S. S. Wong, "Physical modeling of spiral inductors on silicon," IEEE Trans. Electron Device, vol. 47, no. 3, pp. 560-568, Mar. 2000.

[24] R. F. Dana and Y. L. Chow, "The current distribution and AC resistance of a microstrip structure," IEEE Trans. Microw. Theory Tech., vol. 38, no. 9, pp. 1268-1277, Sep. 1990.

[25] D. Kehrer, W. Simbürger, H. D. Wohlmuth, and A. L. Scholtz, "Modeling of monolithic lumped planar transformers up to $20 \mathrm{GHz}$," in Proc. IEEE Custom Integr. Circuit Conf., San Diego, CA, May 2001, pp. 401404.

[26] Y. J. Yoon, Y. Lu, R. C. Frye, and P. R. Smith, "A silicon monolithic spiral transmission line balun with symmetrical design," IEEE Electron Device Lett., vol. 20, no. 4, pp. 182-184, Apr. 1999.

[27] Y. J. Yoon, Y. Lu, R. C. Frye, and P. R. Smith, "Spiral transmission-line baluns for RF multichip module packages," IEEE Trans. Adv. Packag., vol. 22, no. 3, pp. 332-336, Aug. 1999.

[28] J. Y. Ihm and K. P. Hwang, "RF balun embedded in multilayer organic substrate," Microw. Opt. Technol. Lett., vol. 34, no. 4, pp. 255-259, Aug. 2002.

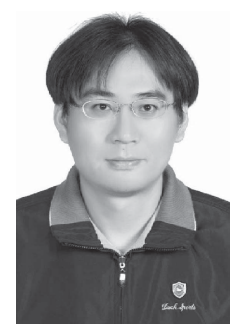

Chien-Hsiang Huang was born in Kaohsiung, Taiwan, on August 24, 1978. He received the B.S.E.E. and M.S.E.E. degrees from National Sun Yat-Sen University, Kaohsiung, in 2000 and 2002, respectively. He is currently pursuing the Ph.D. degree in electrical engineering with the same university.

His current research interests include design and modeling of radio frequency/microwave integrated passive devices.

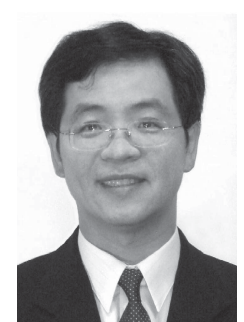

Tzyy-Sheng Horng (S'88-M'92-SM'05) was born in Taichung, Taiwan, on December 7, 1963. $\mathrm{He}$ received the B.S.E.E. degree from National Taiwan University, Taipei, Taiwan, in 1985, and the M.S.E.E. and Ph.D. degrees from the University of California, Los Angeles, in 1990 and 1992, respectively.

$\mathrm{He}$ joined the Department of Electrical Engineering, National Sun Yat-Sen University, Kaohsiung, Taiwan, in August 1992, and was the Director of the Telecommunication Research and Development Center from 2003 to 2008, and the Director of the Institute of Communications Engineering from 2004 to 2007. He is currently a Professor. $\mathrm{He}$ has authored or co-authored over 100 research papers published in refereed journals and conferences proceedings. He holds more than 10 patents. His current research interests include radio frequency (RF) and microwave integrated circuits and components, RF signal integrity for wireless systems-in-package, and digitally assisted RF technologies.

Prof. Horng has served on several technical program committees of international conferences including the International Association of Science and Technology for Development International Conference on Wireless and Optical Communications, the IEEE Region 10 International Technical Conference, the IEEE International Workshop on Electrical Design of Advanced Packaging and Systems, the Asia-Pacific Microwave Conference, the IEEE Radio and Wireless Symposium, and the Electronic Components and Technology Conference. He was the recipient of the Young Scientist Award in 1996 from the International Union of Radio Science, the IndustryEducation Cooperation Award in 1998 from the Ministry of Education, Taiwan, and the Distinguished Electrical Engineer Award in 2010 from the Chinese Institute of Electrical Engineering, Taiwan.

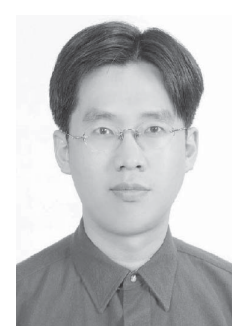

Chen-Chao Wang was born in Miaoli, Taiwan, on February 8, 1973. He received the M.S.E.E. degree in electronic engineering from the National Taiwan University of Science and Technology, Taipei, Taiwan, and the Ph.D. degree in electrical engineering from National Sun Yat-Sen University, Kaohsiung, Taiwan, in 1998 and 2008, respectively.

He was a Research Engineer with Industrial Technology Research Institute, Hsinchu, Taiwan, from 1998 to 2003, where he was involved with the analysis and measurement of high-speed digital systems. In 2006, he joined Advanced Semiconductor Engineering, Inc., Kaohsiung, where he is currently the Department Manager in charge of the Electrical Laboratory. His current research interests include electrical modeling and analysis to power integrity and signal integrity in high-speed digital systems.

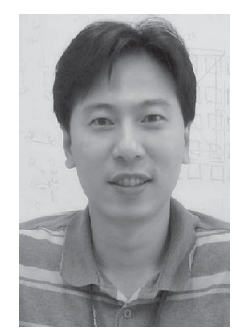

Chi-Tsung Chiu was born in Kaohsiung, Taiwan, in 1974. He received the M.S.E.E. degree from National Sun Yat-Sen University, Kaohsiung, in 2004

$\mathrm{He}$ is currently the Corporate Research and Development Director in charge of system-in-package design and electrical modeling with Advanced Semiconductor Engineering, Inc., Kaohsiung.

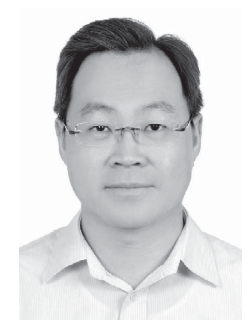

Chih-Pin Hung was born in Taipei, Taiwan, in 1968. He received the Ph.D. degree in electrical and electronic engineering from the University of Paisley, Paisley, U.K., in 1996.

$\mathrm{He}$ is currently the Vice President of the Corporate Design, Research and Development Group, Advanced Semiconductor Engineering, Inc., Kaohsiung, Taiwan, leading the group on product design solutions of integrated technology for systems-inpackage, enabling chips, packages, and system vertical alignment. 